\title{
La colección egipcia del Gabinete de Antigüedades de la Real Academia de la Historia
}

\author{
Andrés DIEGO ESPINEL
}

El Gabinete de Antigüedades de la Real Academia de la Historia, en Madrid, conserva un grupo de 81 piezas egipcias faraónicas procedentes de diferentes donaciones privadas realizadas entre 1858 y 2006. En el presente estudio se presenta una breve historia de la formación de este heterogéneo conjunto. En él destacan tres fragmentos de papiro demótico originarios de Menfis donados por el Baron von Minutoli, los objetos pertenecientes a Pascual de Gayangos, y dos cerámicas predinásticas ofrecidas por George Bonsor provenientes de las excavaciones de W.F. Petrie en Nagada. En conjunto, la serie y su historia ofrecen un buen reflejo de lo que fue el coleccionismo privado de antigüedades egipcias en España en la segunda mitad del siglo XIX.

The Egyptian collection of the Gabinete de Antigüedades of the Real Academia de Historia, Madrid

The Gabinete de Antigüedades (Department of Antiquities) of the Royal Academy of History, in Madrid, holds a group of 81 ancient Egyptian objects from various private gifts made between 1858 and 2006. This study presents a brief account of the creation of this heterogeneous collection. Among its highlights there are three fragments of demotic papyri from Memphis given by the Baron von Minutoli, the Pascual de Gayangos collection and two Predynastic ceramic fragments from the Nagada excavations of W.M.F. Petrie offered to the Academy by George Bonsor. These antiquities and their history clearly reflect the way the private collecting of ancient Egyptian antiquities developed in Spain during the second half of the $19^{\text {th }}$ century.

Key words: Baron von Minutoli, W.M.F. Petrie, P. de Gayangos, G. Bonsor, Memphis, $19^{\text {th }}$ Century Egyptology, Gabinete de Antigüedades

$\mathrm{E}$ ntre su fundación, en 1738, y la del Museo Arqueológico Nacional, en 1867, la Real Academia de la Historia (a partir de ahora $\mathrm{RAH}$ ) fue uno de los centros más importantes en la recepción y estudio de piezas arqueológicas en España, actividades que continuó desarrollando en fechas posteriores y que hoy prosigue. Tal circunstancia ha llevado a que esta institución y, en especial, su Gabinete de Antigüedades, creado en 1763, albergue una de las colecciones más interesantes desde los puntos de vista histórico e historiográfico de materiales arqueológicos del país por su número, calidad y variedad. En ellas se reúnen objetos que van desde el Paleolítico inferior hasta nuestros días. Aunque la mayoría proceden de dentro de nuestras fronteras, el Gabinete también recoge un importante número de piezas foráneas entre las que se incluyen un pequeño lote de 81 objetos egipcios, incluidos algunos falsos $\mathrm{y} / \mathrm{o}$

* El presente artículo es un breve resumen del trabajo realizado por el autor sobre las piezas en la Academia que aparecerá publicado próximamente en uno de los volúmenes del catálogo de antigüedades de dicha institución editado por su actual anticuario, Martín Almagro Gorbea. A él agradezco la oportunidad que me ha dado para poder estudiarlas. También he de agradecer a Jorge Maier (Gabinete de Antigüedades de la RAH), Marilina Betrò (Università degli studi di Pisa), José Manuel Galán (Instituto de Filología, CSIC), Stephen Quirke (University College, Londres), Ezzat Refaei (Macquaire University) y a Ana García Martín la ayuda tan beneficiosa como generosa que me han ofrecido a lo largo de mi trabajo.

Fecha de recepción: 9 de enero de 2007

Fecha de admisión: 25 de junio de 2007

http://doi.org/10.25145/j.TdE.2009.05.01.17 
de antigüedad dudosa ${ }^{1}$. Como la mayor parte de los fondos de la Academia, este conjunto está formado en su totalidad por materiales procedentes de diferentes donaciones particulares. Por ello, tienen, dejando a un lado su valor histórico y artístico, un gran interés para trazar tanto el desarrollo del tan pequeño como mal conocido coleccionismo privado de piezas egipcias, como los primeros pasos de la Egiptología en España en una etapa muy temprana de su historia: el período entre 1858 y el inicio del siglo $\mathrm{XX}$.

\section{EL SIGLO XIX}

Exceptuando varios objetos cuyo origen y fecha de ingreso se desconocen, las primeras piezas que entraron en el Gabinete lo hicieron en un momento que, aunque tardío para otros países europeos, era muy temprano en España en lo relacionado con la adquisición de antigüedades faraónicas, actividad que sólo comenzaría a tomar cierto empuje, siempre por iniciativas y donaciones privadas, a partir de la creación del Museo Arqueológico Nacional en $1867^{2}$. Los primeros aegyptiaca registrados en la Academia llegaron en 1858 a través de dos donaciones. La primera, formada únicamente por un pequeño escarabeo, fue ofrecida por Miguel Tenorio. La segunda, un número impreciso pero reducido de piezas, fue regalado por el Barón Julius Rudolph Ottomar von Minutoli (1804- de la época como el Barón de Minutoli. Este personaje era el primogénito del célebre Barón Johann Heinrich Benjamin Menu von Minutoli (1772-1846), director de la expedición científica enviada por el rey Federico Guillermo III de Prusia a Egipto entre 1820 y $1821^{4}$.

El escarabeo de Miguel Tenorio (posiblemente el diputado Miguel Tenorio de Castilla, que en ese mismo año, 1858, pasaría a ser secretario personal y amante de Isabel II) (fig. 1) es un buen ejemplo de una de las formas más habituales de adquisición de piezas faraónicas por los coleccionistas españoles del XIX: su compra como resultado de un viaje al Oriente Próximo y, en concreto, a Tierra Santa. El objeto ( $\mathrm{n}^{\mathrm{o}}$ inv. 110) formó parte de una donación compuesta, según las Noticias de las Actas de la Real Academia de la Historia leídas el 20 de junio de 1858, por varias monedas "recogidas en su viaje a la Palestina" y "una moneda pequeña de vidrio, de las usadas en Egipto durante los Fatimitas"5. El escarabeo, netamente egipcio y quizás del Reino Nuevo, tiene inscrito un trigrama criptográfico de Amón en su chatón. Por su procedencia bien pudo ser descubierto en Tierra Santa, donde los materiales de este tipo no son raros, o bien ser llevado allí desde el Valle del Nilo siguiendo los oscuros meandros del comercio de antigüedades. No habría que excluir tampoco que su donante pudiera haberlo adquirido en el país de las pirámides durante una breve escala (por ejemplo, en Alejandría) yendo o regresando de Palestina.

1. De este listado se han excluido las piezas presuntamente egipcias descubiertas en Tarragona. Sobre ellas, véase la bibliografía dada en la nota 6 .

2. Para un estudio sobre la formación de las colecciones egipcias de esta institución, véase Pérez Die, 1993: 160, quien indica que las piezas faraónicas del MAN que llegaron a España antes de la fundación del museo parecen haberlo hecho en el siglo XVIII, consistiendo sobre todo en las donaciones de Pedro Franco Dávila (1711-1786) que adquirió sus objetos egipcios en París procedentes, en parte, de la extensa colección reunida previamente por el Conde de Caylus (1692-1765); véase al respecto también Mañueco Santurtun, 1993: 202-208.

3. Para una biografía de este personaje, véase Minkels, 2003.

4. Sobre esta expedición véase Karig, 1998.

5. Sabau, 1858: 5-8. 

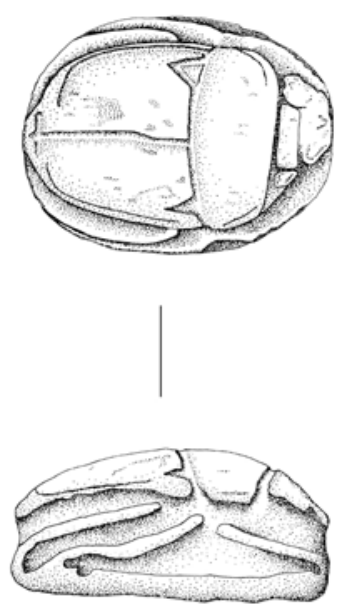

(con momia incluida) de la "tumba egipcia" o "de Heracles" en Tarragona y de otros supuestos aegyptiaca en torno a la ciudad catalana entre 1851 y $1853^{6}$. Tales hallazgos fueron debidos a uno de los pioneros de la arqueología científica en la península: el fundador del Museo Arqueológico de Tarragona, Buenaventura Hernández de Sanahuja (1810-1879), a quien probablemente haya que considerar el creador y/o principal promotor de dicho engaño.

El descubrimiento del presunto sepulcro tuvo cierta repercusión en los ambientes intelectuales de la época captando rápidamente la atención e interés de la RAH, que fue informada puntualmente de la evolución de las excavaciones por el propio Sanahuja ${ }^{7}$. Pese a que estas piezas, de extremada naïveté, no tenían nada que ver con el arte egipcio, fueron identificadas como tales por un erudito tan reconocido como Antonio Delgado y Hernández (1805-1879), Anticuario de la Academia entre 1848 y 1867. Que este sabio valorase de forma tan errónea como inocente estos descubrimientos no fue debido tanto a su presunta incompetencia - fue uno de los historiadores españoles de la Antigüedad más capaces

Figura 1. Escarabeo con trigrama de Amón (o tetragrama de Amonet) (Gabinete de Antigüedades, RAH, $n^{o}$ inv. 110) (dibujo de Ana García Martín)

La pequeña colección ofrecida por el Barón von Minutoli está mucho peor documentada -generalmente la información de la Academia sobre las donaciones durante este período es sucinta- y tiene un origen más atípico al asociarse a uno de los episodios más extraños acaecidos en el inicio de la Egiptología o, mejor dicho, de la Egiptomanía en España: el descubrimiento de su tiempo- como al desconocimiento, ya por entonces endémico, que los eruditos españoles tenían de la Egiptología. En este sentido es paradójico ver que si bien el interés por Egipto y la disciplina que lo estudiaba fueron prácticamente nulos, no lo fue así el que se prestó a la creciente importancia y prestigio internacional que dichas iniciativas estaban adquiriendo en otros países europeos. La credulidad e interés de los académicos españoles ante estos objetos y otros similares fue, por tanto, el resultado del desafortunado encuentro del tan persistente como

6. El descubrimiento de Tarragona no parece haber el único caso de falsificación egipcia de esa época. Se conocen hallazgos similares en Mallorca entre 1832 y 1844 e identificaciones erróneas de restos arqueológicos como egipcios en diferentes lugares de España. Sobre tales hallazgos, véase Marcos Alonso y Pons Mellado, 1996: 166-167.

7. Para esas piezas y las litografías, véase Almagro-Gorbea en Almagro Gorbea (ed.), 2003: 323-328 (F-99 - F-109; F$110 \mathrm{~A}-\mathrm{F}-115 \mathrm{~A}$ ); sobre el supuesto hallazgo y su historia posterior, véase Marcos Alonso y Pons Mellado, 1996; véase igualmente la semblanza de Sanahuja realizada por Almagro Gorbea en Almagro Gorbea (ed.), 2003: 441-442. 
inexplicable desconocimiento y desinterés por la Egiptología en el país en esas fechas y del deseo, a falta de capacidad o de curiosidad por realizar iniciativas científicas serias al respecto, de vincular fuese como fuese la civilización egipcia, como si de la fenicia, griega o romana se tratara, al pedigrí histórico peninsular ${ }^{8}$.

El imprudente afán por embarcarse a bombo y platillo en la aventura egiptológica europea llevó a la RAH a mostrar un profundo interés por los hallazgos tarraconenses e, incluso, a apoyar dichas excavaciones ya que:

(...) nuestro monumento de carácter egipcio llega á sazon de que pueda sacarse de él gran fruto, asi para la historia particular de España, á cuyos sucesos primeros, mas notables y oscuros parece que se refiere, como para la humanidad.

Pero este monumento, como nuevo y desconocido, exige muy detenidos y serios estudios, á que ha abierto honrosamente camino el Sr. Hernandez. La Academia ha acordado promoverlos y apoyarlos, estando dispuesta á hacer al efecto las impresiones y costosos litografiados de colores que sean necesarios, para poner aquellos singulares cuadros al alcance de todas las personas capaces de ayudar á la ilustración de los importantes sucesos á que se refieren $(\ldots)^{9}$.

Estas resoluciones llevaron a la Academia a destinar en 1852 una considerable suma de dinero (8600 reales) para la realización de varias litografías realizadas por Federico Kraus para divulgar al mundo tan extraordinario hallazgo ${ }^{10}$. Afortuna-

[224 ] damente, los ecos del descubrimiento llegaron a oídos del Barón de Minutoli quizás de mano del propio Sanahuja. El que poco antes fuese el $\mathrm{Po}$ lizeipräsident de Prusia encargado de sofocar la revolución berlinesa de 1848, detentaba en esas fechas el cargo de Cónsul General en España y Portugal del Reino de Prusia (lo sería entre 1851 y 1859 , momento en que partió en misión diplomática a Irán muriendo en un caravasar persa ese mismo año). Posiblemente familiarizado con el arte y cultura faraónicas por la importante colección de objetos faraónicos recogida por su padre durante la expedición prusiana a Egipto entre 1820 y 1821, el Barón debió de dudar desde el primer momento del origen y naturaleza egipcias de los materiales encontrados en Tarragona aunque, curiosamente, nunca tuvo dudas de su presunta antigüedad. De este modo, tras consultar a diferentes sabios en Prusia, realizó un estudio minucioso que, firmado en Barcelona el 12 de Junio de 1852, expuso en un discurso presentado por escrito a la Academia y que se conserva en la biblioteca de dicha institución. En ese informe el Barón demostraba que las piezas no eran egipcias aunque, en vez de dudar de su autenticidad, sugería que eran ejemplos "de la representación y del culto del Heracles lybio $=$ feniceo comprendido y ejecutado en el sentido gnosticos, de la epoca de los ultimos Emperadores romanos"11. Pese a su encarada defensa de la legitimidad de los materiales hallados y de la honestidad de Sanahuja, el diplomático prusiano reconocía que la Sociedad Arqueológica de Berlín, a la que había presentado diferentes dibujos de los objetos, había considerado sin dubitaciones que:

Todo es una falsificacion, una imitation de los vasos feniceos, por la cual un compatriota tarraconense parece haber querido superar la gloria epigrafica de Malta y Corfu en cuanto de la falsification del arte.

8. Un buen ejemplo de ello son también las falsificaciones del Cerro de los Santos y la búsqueda de una conexión entre la cultura egipcia y la íbera en torno a 1860; véase Pérez-Accino y Sevilla Cueva, 2003.

9. Sabau, 1851: 8 .

10. Almagro Gorbea en Almagro Gorbea (ed.), 2003: 328-329 (F-110A), subraya esa importante suma en comparación con la de los 1000 reales invertidos poco tiempo antes por la Academia para ilustrar la publicación del disco de Teodosio.

11. Minutoli, 1852: 60-61; Marcos Alonso y Pons Mellado, 1996: 160. 
Ha añadido ademas dicha sociedad q la arqueologia no ha ganado en eso nada sino el conocimiento de su condicion en España ${ }^{2}$.

Gracias a las consideraciones del Barón y a la opinión de los académicos berlineses, la Real Academia de la Historia estuvo a tiempo de suspender la publicación y emisión de las litografias y del informe. Pese a que la institución, siguiendo al prusiano, continuó confiando durante varios años en la autenticidad de "este tesoro arqueológico, digno como ha dicho algun sabio extranjero, de figurar en el primer museo de Europa"13, comenzó a ser mucho más cauta a la hora de atribuirlo como egipcio ${ }^{14}$ llegando, incluso, a solicitar ayuda a otros organismos extranjeros para identificar la cultura a la que pertenecía ${ }^{15}$.
Sólo a partir de 1862, gracias al trabajo de E. W. E. Hübner (1834-1901) ${ }^{16}$ se acabaría reconociendo la falsedad de estos objetos aunque es muy probable que algunos investigadores españoles como Eduardo Toda, el primer ejemplo -deficiente-de egiptólogo español, cayeran, aunque fuera muy brevemente, en el error de seguir considerando las piezas como egipcias $^{17}$.

Como documento, el discurso del Barón von Minutoli también es de gran interés para el estudio de la génesis de la Egiptología en España. En sus páginas 58-59 incluye lo que podría ser la primera tabla (incompleta) de jeroglíficos con sus equivalencias fonéticas, en una curiosa mezcla de castellano y alemán, realizada en España (fig. 2) ${ }^{18}$. La importancia

12. Minutoli, 1852: 53-54.

13. López Ballesteros, 1859: 44.

14. En López Ballesteros, 1859: 45, se dice “(...) no puede afirmarse que á los egipcios, ese pueblo culto de la Antigüedad, cuyo caudillo se supone allí (el sepulcro de Tarragona) enterrado, sea deudora nuestra patria de los primeros albores de su civilización".

15. Así en López Ballesteros, 1859: 46, el director de la RAH sugería: “(...) debe invitarse á los cuerpos sabios de Europa á que unan sus esfuerzos á los de esta Academia para descubrir cúal sea el verdadero orígen de este sarcófago de tan raro mérito arqueológico, y de tan inmediata aplicación á la historia universal”.

16. Hübner, 1862.

17. Esta suposición, ya sugerida por Marcos Alonso y Pons Mellado, 1996: 164, se basa en las "Noticias" del BRAH $\mathrm{X}$ (1887), 169-170, que menciona siete objetos (entre ellos dos de los relieves asirios conservados en la academia) estudiados por Toda entre los que se incluían “(...) varios monumentos inéditos adquiridos hace algunos años (...). Cuatro de estos monumentos son resueltamente egipcios, y debieron labrarse en los dominios de alguna de las tribus del Asia Menor, sometidas al poder de un Faraón, tebano (...). El último (...) parece estar escrito con un sistema de jeroglíficos, peculiar de varios epígrafes de Siria y del Asia Menor, atribuido a los pueblos meteos, cuyo papel interesante en la historia nos dan á conocer con amplitud sus propios y ajenos monumentos. En la presente lápida su tosco estilo, sus contornos mal delineados y su mezcolanza jeroglífica de animales, formas humanas y signos geométricos, hacen tanto más insegura la leyenda, cuanto que no se ha podido determinar aún el idioma que está llamado á dar la clave del arcano jeteo; pues ni el siríaco, ni el chipriota, ni el asirio, ni otro circunvecino aplicado á la interpretación de tan extraña lengua, ha llegado á producir un resultado satisfactorio". La descripción de Toda es extraña. Conociendo los materiales de la Academia, los que mejor concuerdan con esa descripción son, sin duda, las falsificaciones de Sanahuja. En este sentido es llamativo que en la misma noticia se confirma que "La Academia oyó con agrado y acordó publicar en su boletín el informe de su ilustre correspondiente D. Eduardo Toda, sobre siete monumentos inéditos (...)", cuando, consultando en los índices de boletines posteriores no hay constancia de que el investigador catalán llegara a publicarlo. Ello quizás se deba a que Toda finalmente terminara por darse cuenta de la falsedad de algunas de las piezas no llegando a redactar nunca dicho informe.

18. Minutoli, 1852: 58-59. No tengo conocimiento de ninguna tabla similar realizada en España o en castellano previamente. La única tentativa de traducción jeroglífica, errónea, previa conocida habría sido la realizada por el sacerdote Lorenzo Hervás y Panduro (1735-1809), quien identificó los signos egipcios como parte de una escritura alfabética y su lengua como derivada del hebreo; sobre este autor y otros "proto-egiptólogos" o "egiptómanos", véase Lara Peinado, 1993: 188; sobre el conocimiento (y desconocimiento) del Egipto antiguo en la España de mediados del siglos XIX, véase también Molinero Polo, 2004: 15-17. 
de esta tabla también radica en sus posibles inspiradores ya que, según el mismo informe ${ }^{19}$, el diplomático, en su interés por los textos supuestamente jeroglíficos de los objetos tarraconenses, consultó a cierto "profesor Mowers de la academia de Breslau" (sin duda Franz Carl Movers (1806-1856), profesor titular en la Universidad de Breslau desde 1842) y a un tan joven como ya respetado Heinrich Brugsch $(1827-1894)^{20}$.

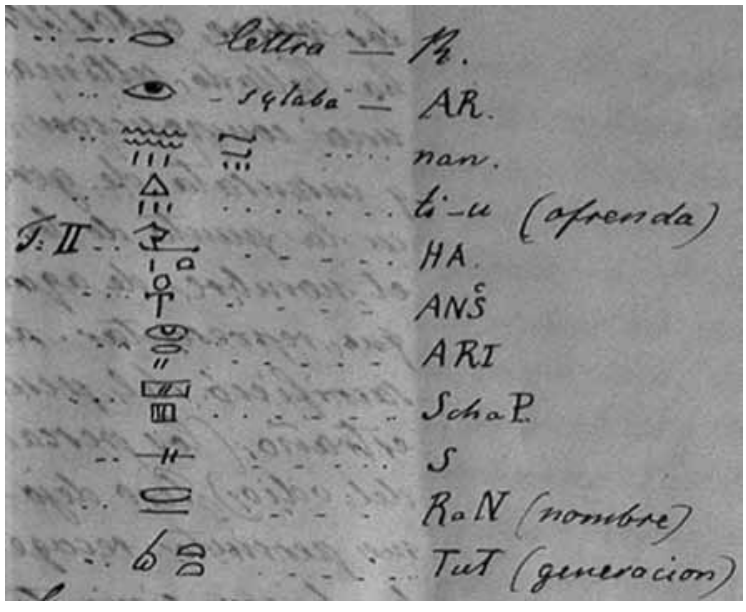

Figura 2. Parte de la tabla de equivalencias conservada en el discurso del Barón von Minutoli (Manuscrito 9/8662 de la Biblioteca de la Real Academia de la Historia) (Fotografía reproducida por cortesía de la $R A H$ )

Como consecuencia de la cordial relación establecida entre el Barón y la RAH a raíz de este suceso, es posible que el primero ofreciese a la institución el ya mentado lote de piezas egipcias en $1858^{21}$. Su origen debió de ser la colección del padre del Barón ya que hay constancia de que su familia conservó parte de ella durante cierto tiempo. Aunque la mayor parte de los objetos fue, por un lado, vendida varias décadas antes en París y, por otro, adquirida por el Museo de Berlín, se sabe que todavía en 1875 uno de sus hijos subastó en Colonia algunas piezas egipcias mantenidas por la familia ${ }^{22}$. No es descabellado, por tanto, pensar que los aegyptiaca de la RAH pudieran ser también algunos de los últimos restos de la importante colección traída desde Egipto casi cuarenta años antes.

Como ya se ha indicado, no es posible precisar con seguridad qué objetos formaron el lote que ingresó en la Academia. Una minuta de oficio fechada en Madrid el 10 de Mayo de 1858 informa someramente de la entrada a la Academia de "una cajita con varios objetos antiguos regalados al cuerpo por el Excmo. Sr. Baron de Minutoli". Las Noticias de las actas de ese mismo año citan, en el apartado de los donativos de monedas y objetos de antigüedad donados por los señores académicos correspondientes, el dado por "EL EXCMO. SR. BARON DE MINÚTOLI. Varios fragmentos de cristal, hallados en las ruinas de Itálica y Mérida, y uno de ellos en Egipto" ${ }^{23}$. Sólo dos de las piezas egipcias están bien documentadas gracias a sendas noticias en el catálogo realizado por García y López en 1903. La más destacable, y sin duda una de las más interesantes de la colección, es un conjunto de tres fragmentos de papiro en escritura demótica ( $\mathrm{n}^{\mathrm{o}}$ inv. 109) (fig. 3) pertenecientes a dos documentos legales diferentes cuyo texto, gracias al estudio de los papiros realizado por la catedrática de Egiptologia de la Università degli studi de Pisa, Marilina Betrò, permite precisar con seguridad su procedencia: el área menfita, y su datación: el año 8 del reinado de Ptolomeo X (107/106 a.C.). La segunda pieza, un escarabeo

19. Minutoli, 1852: 57.

20. Para Brugsch, véase Dawson, Uphill y Bierbrier, 1995: 67-68.

21. GA $1858 / 3$.

22. Se trataba de Alexander von Minutoli (1806-1887); véase Dawson, Uphill y Bierbrier, 1995: 289.

23. Sabau, 1860, 19. La misma noticia aparece en San Miguel, 1859: 20. 

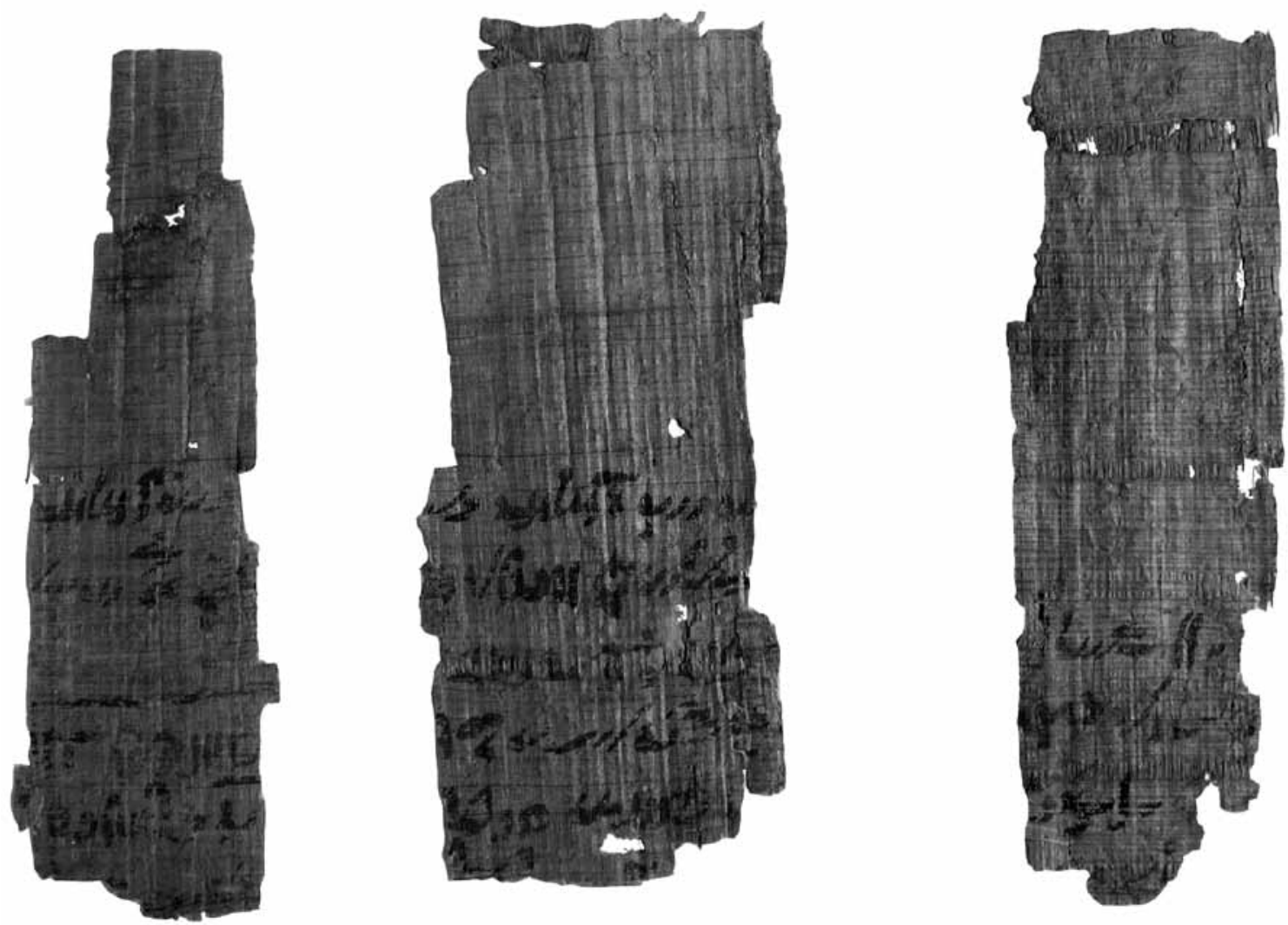

Figura 3. Tres fragmentos de papiro en demótico, recto (Gabinete de Antigüedades, $R A H, n^{\circ}$ inv. 109). Forman parte de dos contratos procedentes del área menfita realizados por el mismo escriba y datados en el año 107/106 a.C. Los fragmentos a la izquierda y en el centro de la fotografía corresponden a un mismo documento (fotografía cortesía del Gabinete de Antigüedades de la RAH)

de piedra cuyo chatón porta una escena faraónica de elaboración moderna ( $\mathrm{n}^{\mathrm{o}}$ inv. 105), no deja de ser una paradoja por tratarse del regalo del desenmascarador de un fraude egiptológico. En cuanto a "los fragmentos de cristal" parecen ser más bien modernos e incluso, quizás, de origen español ${ }^{24}$. A estas piezas quizás habría que añadir otras que, por eliminación, pudieron formar parte de este lote y que aparecen inventariadas sin un origen preciso entre las antigüedades egipcias de la institución en el catálogo realizado en 1903 por García y López ( $\mathrm{n}^{\mathrm{o}}$ cat. 104, 107, 108, 114/1-7).

\section{La Colección GaYangos}

No sería hasta cuarenta años después de la donación de estos objetos, en 1898, cuando la colección de aegyptiaca de la Academia se incrementó. Ese año $D^{a}$. Emilia de Gayangos de Riaño y D. José de Gayangos ofrecieron a dicha institución las antigüedades reunidas por su padre, el académico Pascual de Gayangos y Arce (1809-1897). El único documento conocido referido a este acontecimiento, una carta de los donantes, lo describe con este escueto: 
Tenemos la satisfacción de remitir á V.E., como donativo á la Real Academia la colección de antigüedades formada por nuestro difunto padre don Pascual de Gayangos, esperando que se sirva exponerla con su nombre, como recuerdo de las simpatias, q 1. demostró siempre á esa ilustre Corporación $(\ldots)^{25}$.

Reconocido arabista e hispanista, el sevillano Pascual de Gayangos fue un importante personaje dentro de la cultura española del siglo XIX. Su trabajo, desarrollado en gran medida en Inglaterra, concretamente en el Museo Británico, y su herencia, un importante conjunto de libros que actualmente se conserva en la Biblioteca Nacional de Madrid, constituyen una de las principales bases de los estudios orientales -especialmente árabes- en España. Menos conocidas, pero no por ello menos desdeñables que su obra científica, son las antigüedades que donó a la Academia. Iniciada por su padre, esta colección está formada por un gran número de piezas de origen diverso que abarca desde el Egipto faraónico hasta la América Precolombina pasando por Grecia y Roma e incluye otras rarezas como el único vaso minoico conservado en España ${ }^{26}$.

Como en el caso de la donación del Barón von Minutoli, las circunstancias precisas de la adquisición de estos objetos son desconocidas. Respecto a los materiales egipcios, que constituyen más de dos tercios del total de aegyptiaca conservados en la Academia, es posible que fueran adquiridos en los mercados de anticuarios de Londres, donde en algún hipotético viaje a Egipto donde pudo desplazarse por su oficio como arabista.

Entre las piezas de la colección, en su mayoría objetos de fayenza (amuletos, elementos de mallas de momia, etc) y bronces, cabe destacar un nutrido grupo de ushebtis, algunos de ellos con epígrafe, entre los que destacan los dos más antiguos: un ushebti de madera de Sethy I, rey de la dinastía XIX, y otro de fayenza de una mujer llamada Mutemuia $\left(\mathrm{n}^{\mathrm{o}}\right.$ inv. 785) que vivió a caballo entre las dinastías XX y XXI. Ambos parecen proceder de diferentes descubrimientos en la zona de Tebas durante las dos primeras décadas del siglo XIX. La tumba de Sethy I fue descubierta por Belzoni en 1817 mientras que la cachette de donde procedería el ushebti de Mutemuia debió de ser hallada entre 1815 y 1818 (algunas piezas de su ajuar formaron parte de la colección del Barón von Minutoli padre y en la actualidad se encuentran en Berlín). Entre los otros objetos cabe destacar un fragmento de calado en madera de momia probablemente de época ramésida ( $\mathrm{n}^{\mathrm{o}}$ inv. 804), algunos bronces con imágenes de diferentes divinidades entre los que destaca, por su rareza, la figura de un donante sedente sosteniendo una imagen de Harpócrates ( $\mathrm{n}^{\mathrm{o}}$ inv. 806), una sítula ( $\mathrm{n}^{\mathrm{o}}$ inv. 805) del tipo III de Lichteim (fig. 4) o un escarabeo de fayenza de fina factura con el praenomen de Tutmés III, Menjeperre ( $n^{\circ}$ inv. 1020/65).

\section{Otras donaciones del final del siglo XIX e INICIOS DEL SIGLO XX}

Entre 1898, el mismo año de la llegada de la colección Gayangos, y 1902, la Academia

25. GA 1898/1 (2), oficio emitido el 27 de enero de 1898. Véanse en relación con tal donación GA 1898/1 (1)-(4).

26. Para la donación de D. Pascual Gayangos a la RAH, véase Almagro-Gorbea, 1999: 38, quien ofrece más bibliografía sobre dicho personaje. Véase también Escribano Martín, 2006a: 258. Para el askos minoico, véase Almagro Gorbea: 2003.

27. Esta sospecha está inducida por la presencia en dicha colección de un ushebti ( $\mathrm{n}^{\circ}$ inv. 777 ) con una etiqueta descriptiva escrita en castellano. El hecho de que en el resto de la colección Gayangos sea raro este tipo de etiquetas permite suponer -aunque con todas las reservas- que pudo ser obtenida en algún negocio de anticuariado español por su propietario. 


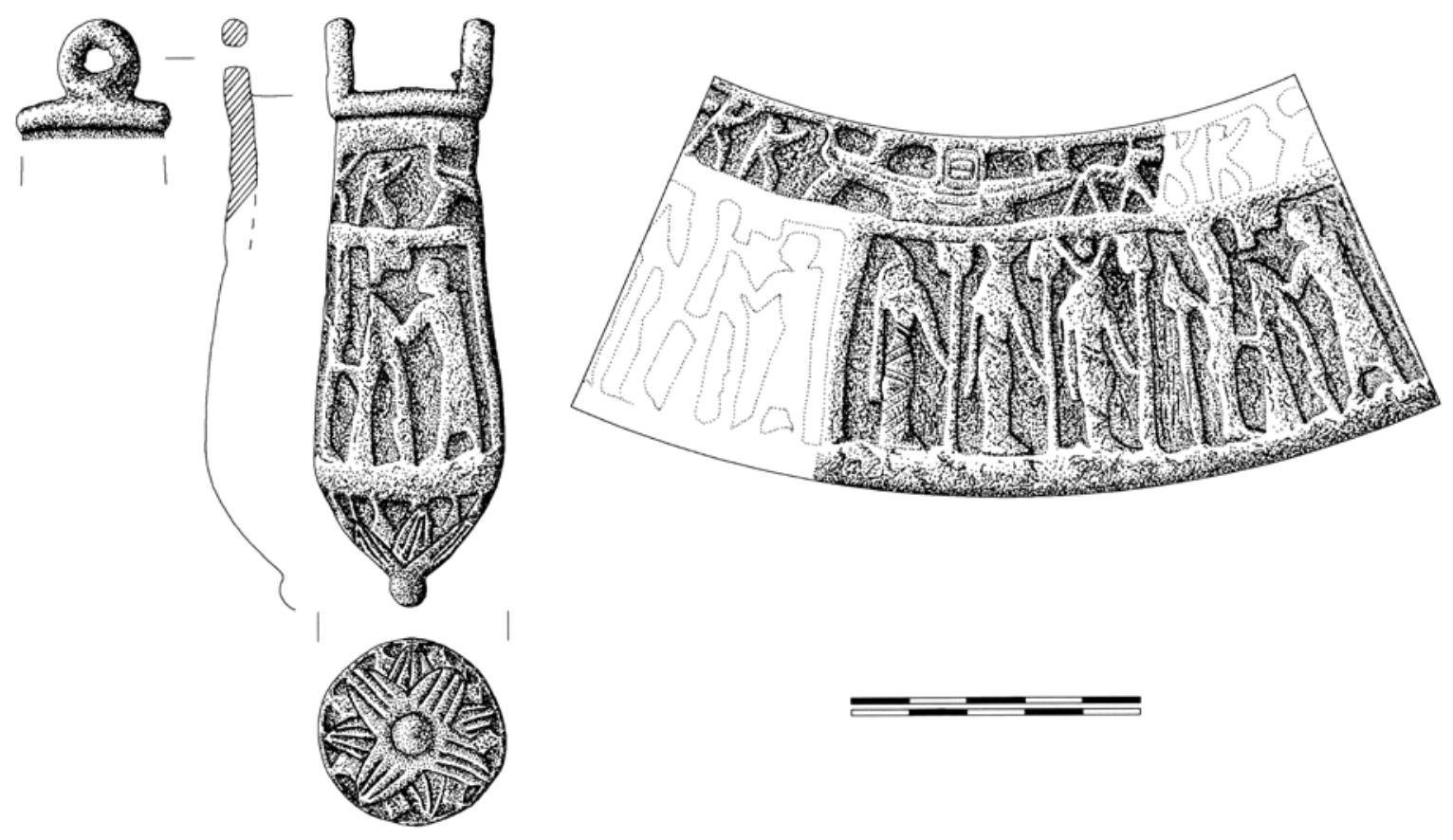

Figura 4. Situla de bronce de la colección Gayangos (Gabinete de Antigüedades, RAH, $n^{\circ}$ inv. 805) (dibujo de Ana García Martín)

recibió otras donaciones, más modestas, de piezas egipcias. Dos de ellas muestran el escaso ojo de los coleccionistas españoles para adquirir antigüedades faraónicas ya que están formadas, sobre todo, por falsos.

La primera $\left(\mathrm{n}^{\mathrm{o}}\right.$ inv. 106), consistente en un grupo escultórico que es una evidente falsificación, fue realizada en 1898 por $\mathrm{D}^{\mathrm{a}}$ Manuela Redondo, viuda del académico correspondiente en San Sebastián, Antonio Bernal de O’Reilly (1820-1897), quien desempeñó el cargo de cónsul general en Siria entre 1863 y $1866^{28}$.
La segunda ( $\mathrm{n}^{\mathrm{o}}$ inv. 100 y 115) fue realizada en 1902 por Antonio de Aguilar y Correa, Marqués de la Vega de Armijo (1824-1908), por entonces director de la Academia (1895-1908). Las dos piezas, ofrecidas por el que fuese fugazmente jefe de gobierno entre el final de 1906 e inicios de 1907 , son dos esculturas de piedra. Una de ellas ( $\mathrm{n}^{\mathrm{o}}$ inv. 100) es tan tosca que en el inventario realizado en 1903 no fue reconocida como egipcia. La otra $\left(\mathrm{n}^{\mathrm{o}}\right.$ inv. 115) es la parte superior de una figura humana masculina inacabada de gran calidad probablemente del Período Tardío o del Grecorromano, aunque ciertos detalles no permiten certificar con seguridad su autenticidad.

28. De dicha donante también procede el retrato de Isabel la Católica atribuido a Juan de Flandes, que ingresó en la RAH en 1897. De acuerdo a GA 1899/1 (2), una minuta de oficio sin fecha, la pieza egipcia llegó con otras adquiridas por Bernal de O'Reilly en Palestina, Siria y Egipto. Véanse GA 1899/1 (1) y GA 1899/1 (3), que mencionan varios objetos entre los que se cuentan varios pendientes y joyas de oro "encontrados en varios sarcófagos de la epoca en que los Asirios y Despues los Romanos ocuparon la antigua Siria" (GA 1899/1 (3), folio 4). El propio Bernal de O'Reilly es autor de una obra referida a Egipto: Bernal de O'Reilly, 1876. Para este personaje, véase Escribano Martín, 2006b: 170-171. 
La más interesante, en términos historiográficos, de todas las pequeñas donaciones realizadas a la Academia en torno al inicio del siglo XX, fue la ofrecida por el arqueólogo anglo-francés Jorge Bonsor (1855-1930) en 190029. Las circunstancias que rodean su entrega hacen de ella uno de esos raros ejemplos en los que la Egiptología española de inicios del siglo pasado -si es que existía en ese momento- mantuvo algún contacto, indirecto, con algún representante o institución de la disciplina en el extranjero ${ }^{30}$. El lote regalado por Bonsor estaba formado por dos fragmentos cerámicos entregados a este pionero de la arqueología científica en España por el padre de la arqueología egiptológica, el británico W.M. Flinders Petrie (1853-1942), de quien el primero tomaría numerosos logros como el cross-dating method y las consiguientes sequences dates.

Gracias a la correspondencia conservada por el primero, actualmente archivada en su casamuseo en Mairena del Alcor (Sevilla), se sabe que, al menos a lo largo del año 1900, ambos investigadores intercambiaron, por carta y en persona, información sobre diferentes tipos de cerámica. A raíz de sus hallazgos en diferentes excavaciones y prospecciones por la Andalucía Occidental, Bonsor contactó con Petrie para contrastar sus ideas sobre la datación de ciertas cerámicas fenicias y, también, sobre las campaniformes que originalmente creyó que estaban asociadas a una posible invasión céltica en el propias experiencias excavando algunos megalitos llevarían finalmente a Bonsor a datar esos artefactos en fechas más tempranas a las que él mismo había considerado previamente, aunque nunca llegara a ceñirse del todo a las propuestas, siempre más certeras, del egiptólogo inglés.

El diálogo establecido entre los dos arqueólogos en torno a la cultura campaniforme, en ese momento una línea de investigación prometedora dentro de las ideas difusionistas imperantes en la Arqueología, llevó al intercambio de materiales. La correspondencia de Bonsor indica que Petrie recibió de él fotografías y, probablemente también, hallazgos originales de sus excavaciones en España llevados por el propio Bonsor en una de sus visitas estivas regulares a Inglaterra $^{31}$. Es muy posible que, debido a esa razón, Petrie ofreciera al franco-inglés los dos galbos egipcios que pasaron inmediatamente a manos de la RAH y que, según Bonsor, formarían parte de los hallazgos realizados por Petrie en Nagada durante 1895.

Ambas piezas ( $\mathrm{n}^{\mathrm{o}}$ inv. 1081/1-2) son dos buenos ejemplos de lo que Petrie denominó como $N$ (ubian)-ware, de cronología Nagada IIA-B (c 3650 - 3400 a.C.) (fig. 5) $)^{32}$. Su origen, por su distribución, parece ser, pese a su nombre, egipcio aunque también se documentan ejemplos en la Baja Nubia. Una de las cerámicas ( $n^{\circ}$ inv. 1081/1) lleva la sigla B25 que podría indicar que era originaria de la tumba 25 de la necrópolis $B$ de Nagada (Kom Belal) ${ }^{33}$, aunque, por desgracia,

29. Sobre la obra de Jorge Bonsor, véase Maier, 1999a.

30. Para otro ejemplo de estos contactos, el intercambio de piezas egipcias del Museo de Liverpool por diversos azulejos vidriados españoles del Museo Municipal de Bellas Artes de Santa Cruz de Tenerife en 1905, véase Martín del Río Álvarez y Almenara Rosales, 2002.

31. Sobre dichos contactos, veáse Maier, 1999a: 124; sobre la correspondencia, véase Maier, 1999b: 35-36 (31), fig. 9, (carta de Petrie a Bonsor del 10/4/1900); 38-39 (38) (carta de Bonsor a Petrie del 29/6/1900); 39 (39) (carta de Petrie a Bonsor del 7/1900).

32. Para un estudio reciente de la N-Ware, véase Glück, 2007.

33. Petrie y Quibell, 1896: 23, lám. 86. 

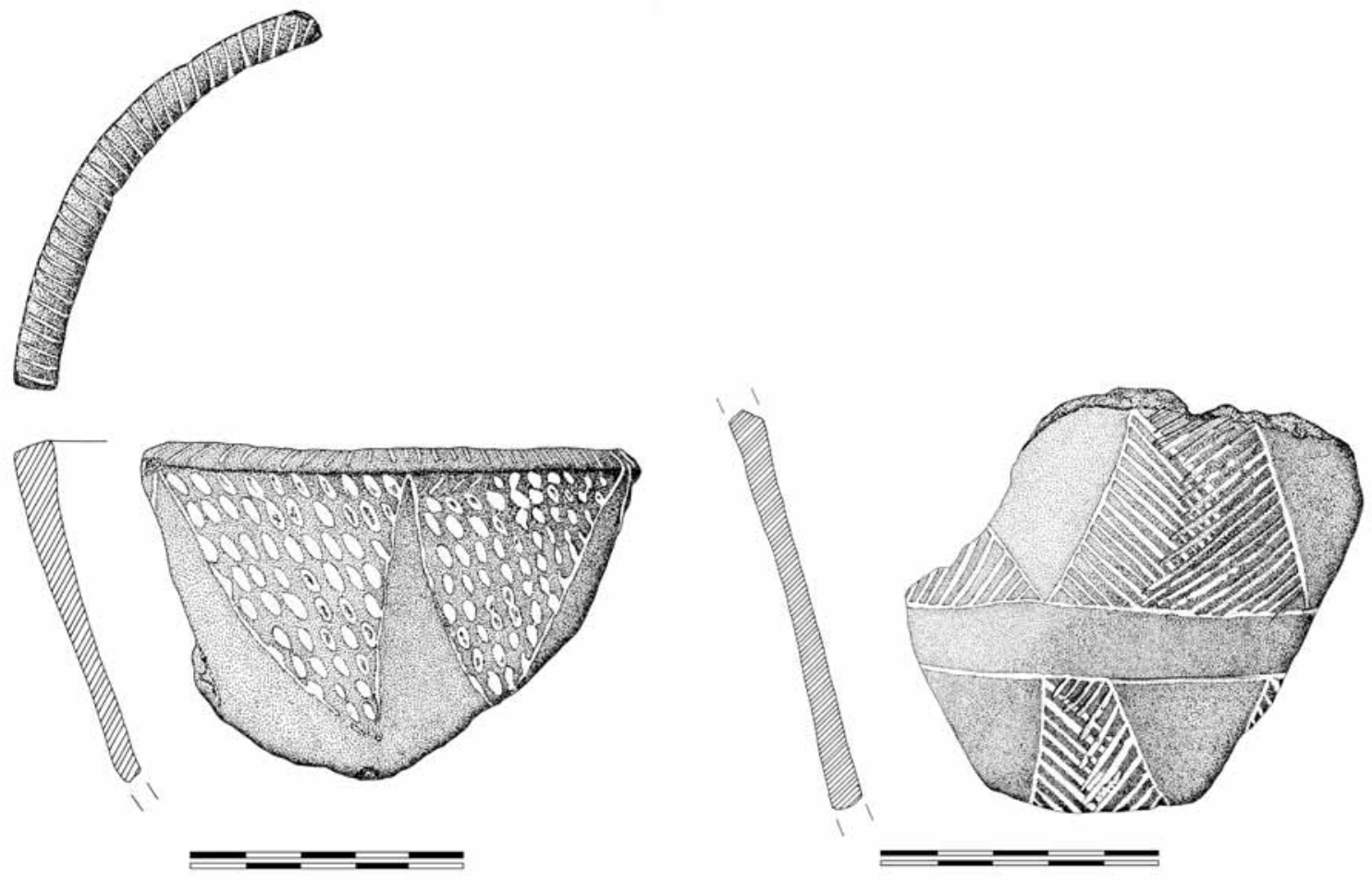

Figura 5. Cerámicas predinásticas procedentes de las excavaciones de Petrie en Nagada y ofrecidas a la Academia por George Bonsor. El ejemplar de la izquierda, que porta la sigla B25, corresponde al borde decorado de un cuenco del tipo N15 (Gabinete de Antigüedades, RAH, $n^{\circ}$ inv. 1081/2) mientras que el segundo corresponde a un vaso del tipo N30 de Petrie (Gabinete de Antigüedades, RAH, $n^{\circ}$ inv. 1081/2) (dibujo de Ana Garcia Martín)

en el croquis de la tumba realizado por Petrie, conservado en el University College de Londres, no es posible identificar este objeto ${ }^{34}$.

\section{La COLECCIÓN EgIPCIA DE 1903 HASTA NUESTROS DÍAS}

Todos los objetos dados en estas donaciones, así como otros de procedencia desconocida, fueron recogidos en el primer inventario de materiales conservados en el Gabinete de Antigüedades realizado en 1903 por el entonces Anticuario
José Catalina García y López (1845-1911). Este estudio, basado en una somera descripción por escrito de cada pieza, muestra algunos rasgos sorprendentes. Mientras que en la relación de algunos objetos García y López muestra una falta de familiaridad tan comprensible como grande de la arqueología egipcia, en otras incorpora ciertos términos que permiten sospechar el uso de bibliografía especializada como es el caso de la mención del claft o del nemes. Un buen ejemplo de ambos aspectos es su comentario sobre un amuleto en forma de pilar dyed que describe como "Tat ó Dad, comúnmente llamado

34. Agradezco esta información a S. Quirke (Petrie Museum, Londres) y a Ezzat Refaei (Macquaire University, Sydney). Según me ha sugerido Refaei, B25 también podría aludir a la tumba 25 de la necrópolis B de Abadiya, excavada por Petrie entre 1898-1899; sobre esta necrópolis, véase Petrie, 1901: 32-34. Menos posiblemente B25 podría ser una signatura realizada por el propio Bonsor para clasificar sus materiales de estudio. 
Nilómetro, porque se dice que era copia de las columnas que servían para medir la altura de las aguas del Nilo (...)"35.

La aparición del inventario coincidiría en el tiempo con una importante interrupción en el ingreso en la RAH de piezas egipcias. Con la donación en 1902 de las piezas del Marqués de la Vega de Armijo no se incorporarán más aegyptiaca al Gabinete durante casi un siglo aunque es posible que en un momento de ese período llegaran (o se redescubrieran) algunos objetos ( $\mathrm{n}^{\mathrm{o}}$ inv. 1223/3-6; 18-19) de procedencia desconocida. Esa paralización, sólo interrumpida con la donación de dos bronces en el año 2000 por el secretario perpetuo de la Academia, D. Eloy Benito Ruano ( $\mathrm{n}^{\circ}$ inv. 2000/24/1-2), no deja de ser paradójica porque coincide con el momento en el que la Egiptología comienza a desarrollarse en España primero intermitente y tenuemente y después, en los últimos años del siglo, de una forma mucho más intensa, sólida y seria.

A partir del año 2003, por iniciativa del actual Anticuario perpetuo del Gabinete de Antigüedades, D. Martín Almagro Gorbea, se ha iniciado el estudio completo de los materiales egipcios de la RAH siguiendo la línea recientemente inaugurada de catalogación, análisis y publicación integrales de la amplísima colección de piezas arqueológicas conservadas en esta institución. Además de una importante mejora en la exposición de algunos de los objetos más destacables en las salas nobles de la Academia, los aegyptiaca han sido, de momento, objeto de dos estudios que tienen como fin tanto su análisis y valoración como, también, el darlos a conocer al público. El primero, incluido dentro del catálogo de epigrafes prerromanos es aquél realizado por José Manuel Galán sobre las inscripciones faraónicas $^{36}$. El segundo, realizado por quien escribe en colaboración con Marilina Betrò, que ha estudiado los fragmentos de papiro demóticos, consiste en el catálogo general de todos los materiales del Egipto antiguo que será incluido dentro de un volumen conjunto también dedicado a las antigüedades clásicas y americanas y que en el momento de la redacción de este artículo se encontraba en prensa.

En resumen, los materiales faraónicos de la RAH representan, tanto por su número (pequeño pero considerable dentro del conjunto, bastante escuálido, de colecciones egipcias en España) como por su historia, una significativa muestra del interés heterogéneo e irregular que el Egipto antiguo ha despertado entre anticuarios, políticos y sabios españoles a lo largo de casi siglo y medio. Un último y buen ejemplo de esa curiosidad es la última pieza que, de momento, ha engrosado la lista de antigüedades faraónicas en la Academia. Se trata de un escarabeo que formaba parte de las pertenencias personales del antiguo director de esta institución, D. Emilio García Gómez (1905-1995) y que fueron donados a la RAH en el 2006. La adquisición de este objeto ( $\mathrm{n}^{\mathrm{o}}$ inv. 2006/4/2) por ese eminente arabista, sin duda ya reconocida por él como uno de los tantos souvenirs que invaden cada rincón de Egipto, probablemente tuvo como origen la misma mezcla de fascinación, atracción y simpatía que despierta ese país y que llevó a los donantes que le precedieron a adquirir los objetos que, por diferentes avatares, han terminado formando la colección, tan heterogénea como interesante, que se conserva en el Gabinete de Antigüedades. 


\section{Bibliografía}

AA.VV.

2001 Tesoros de la Real Academia de la Historia. Madrid.

Almagro-Gorbea, M.

1999 El gabinete de antigüedades de la Real Academia de la Historia, en AlmagroGorbea (ed.), 1999: 15-173.

2003 Un askos minoico en la Real Academia de la Historia de Madrid, Archäologische Anzeiger 2003/1: 117-128.

Almagro-Gorbea, M. (ED.)

1999 El gabinete de antigüedades de la Real Academia de la Historia. Madrid.

2003 Epigrafía Prerromana: Catálogo del Gabinete de Antigüedades. R.A.H. I.1.1. Madrid.

Bernal de O'Reilly, A.

1876 Viaje a Oriente: en Egipto. Madrid.

Córdoba Zoilo, J.M ${ }^{\mathrm{a}}$; Pérez Die, $\mathrm{M}^{\mathrm{a}}$ C. (CoOrds.) 2006 La aventura española en Oriente (11662006). Viajeros, museos y estudiosos en la historia del redescubrimiento del Oriente Próximo Antiguo. Madrid.

DAwson, W.R.; UphiLl, E.P.; BIERBriER, M.L.

1995 Who was who in Egyptology. Third Revised Edition. London.

EsCribano MARTín, F.

2006a Pascual de Gayangos (1809-1897) y los orígenes del Orientalismo, en Córdoba Zoilo y Pérez Die (coords.): 258.

2006b Antonio Bernal de O'Reilly (1820-1897): un cónsul en Siria y Líbano, en Córdoba Zoilo y Pérez Die (coords.): 170-171.
García y LóPez, J. C.

1903 Inventario de las antigüedades y objetos de arte que posee la Real Academia de la Historia, Boletín de la Real Academia de la Historia 42: 311-316, 321-368, 484505; Boletín de la Real Academia de la Historia 43: 257-322.

Galán Allué, J. M.

2003 Inscripciones egipcias, en AlmagroGorbea (ed.), 2003: 461-470.

GLÜCK, B.

2007 Die ,nubische N-Ware' - eine nubische Ware?, MDAIK 63: 9-41.

HÜBNER, E.

1862 Die antiken Bildwerke in Madrid. Madrid.

KARIG, J.S.

1998 A Prussian Expedition to Egypt in 1820: Heinrich von Minutoli, en Starkey, P. y Starkey, J. (eds.): Travellers in Egypt, London: 70-74.

Lara Peinado, F.

1993 Un cultivador de la Egiptología: José Ramón Mélida, BAEDE 3: 188-193.

Lichteim, M.

1947 Situla no. 11395 and some Remarks on Egyptian Situlae, JNES 6: 169-179.

LóPEZ BALLESTERos, L.

1859 Discurso leido á la Real Academia de la Historia por su director, el Excmo. Sr. D. Luis Lopez Ballesteros, al concluir el trienio de su dirección en 1852. Madrid. 
MAIER, J.

1999a Jorge Bonsor (1955-1930). Un académico correspondiente de la Real Academia de la Historia y la Arqueología Española. Madrid.

1999b Epistolario de Jorge Bonsor (1886-1930). Madrid.

2005 Antigüedades siglos XVI-XX. Catálogo del Gabinete de Antigüedades. R.A.H. 1.2.4. Madrid.

Mañueco Santurtun, $\mathrm{M}^{\mathrm{a}} \mathrm{C}$.

1993 Colecciones reales en el Museo Arqueológico Nacional, en Marcos Pous (coord.): 189-216.

Marcos Alonso, C.; Pons Mellado, E.

1996 Sobre las falsificaciones egipcias de Tarragona a mediados del siglo XIX, Boletín del Museo Arqueológico Nacional 14: 157-173.

Marcos Pous, A. (COORD.)

1993 De gabinete a Museo. Tres siglos de Historia. Madrid.

Martín del Río Álvarez, C.; Almenara

Rosales, E.

2002 Some materials in Tenerife from Petrie's and Garstang's excavation, $T d E$ 1: 45-54.

MinkeLs, D.

20031848 gezeichnet. Der Berliner Polizeipräsident Julius von Minutoli. Berlin.

[ 234 ] Minutoli, Barón J. DE

1852 El sarcófago de Heracles en Tarragona con miración particular de las colonias más antiguas de España y de las colonias feniceas en lo general (Manuscrito del discurso dedicado a la Real Academia de la Historia, firmado en Barcelona el 12 de Junio de 1852). Madrid.
Molinero Polo, M. Á.

2004 El pozo y el péndulo. La actividad egiptológica de anticuarios y arqueólogos españoles, 1868-1966, en Martín Flores, A. (coord.): Españoles en el Nilo, Madrid: 15-62.

Pérez-Accino, J.R.; Sevilla Cueva, C.

2003 Forgers, Scholars and International Prestige: Ancient Egypt and Spain, en Jeffreys, D. (ed.): Views of Ancient Egypt since Napoleon Bonaparte: Imperialism, Colonialism and Modern Appropriations, London: 95-105.

Pérez Die, $\mathrm{M}^{\mathrm{a}} \mathrm{C}$.

1993 Las colecciones de Egipto y Próximo Oriente, en Marcos Pous (coord.): 159169.

Petrie, W.M.F.

1901 Diospolis Parva. The Cemeteries of Abadiyeh and $\mathrm{Hu}, 1898-1899$. London.

Petrie, W.M.F.; Quibell, J.

1896 Naqada and Ballas. London.

SABAU, P.

1851 Noticias de las actas de la Real Academia de la Historia en los primeros meses de 1851. Madrid.

1858 Noticias de las actas de la Real Academia de la Historia leidas en junta pública de 20 de Junio de 1858. Madrid.

1860 Noticias de las actas de la Real Academia de la Historia leidas en junta pública de $1^{\circ}$ de Julio de 1860. Madrid.

San Miguel, Duque de

1859 Discurso leido á la Real Academia de la Historia por su director el Excmo. Sr. Duque de San Miguel, al terminar el trienio de su dirección en 1858. Madrid. 


\section{Trabajos de Egiptología Papers on Ancient Egypt}

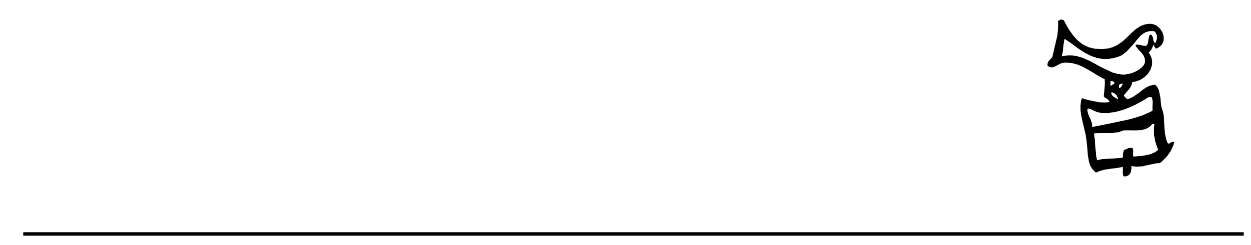

Número 5/1 2009 


\section{Actas \\ III Congreso Ibérico de Egiptología III Congresso Ibérico de Egiptologia}

Editores

Miguel Ángel Molinero Polo Covadonga Sevilla Cueva 


\title{
Editor
}

Miguel Ángel Molinero Polo

Universidad de La Laguna

\section{Consejo Editorial}

\author{
Antonio Pérez Largacha \\ Universidad de Castilla-La Mancha \\ José-R. Pérez-Accino \\ Birkbeck, Universidad de Londres \\ Covadonga Sevilla Cueva \\ Universidad Autónoma de Madrid
}

\section{Comité Científico}

Josep Cervelló i Autuori

Universitat Autònoma de Barcelona

$\mathrm{M}^{\mathrm{a}}$ José lópez Grande

Universidad Autónoma de Madrid

Josep Padró i Parcerisa

Universitat de Barcelona

$\mathrm{M}^{\mathrm{a}}$ Carmen Pérez Die

Museo Arqueológico Nacional, Madrid

Ester Pons Mellado

Museo Arqueológico Nacional, Madrid

José M. Serrano Delgado

Universidad de Sevilla

\section{Colaboradores Editoriales}

Linda Steynor

English editorial assistant

Hervé Mouriacoux

Assistant éditorial pour la langue française 
Trabajos de Egiptología está producida por Isfet. Egiptología e Historia c/ Blanco $1,2^{\circ}$

38400 Puerto de la Cruz

Tenerife-Islas Canarias

España

Maquetación: Proyecto Limón

(C) Autores de los artículos aparecidos

y Consejo Editorial de Trabajos de Egiptología - Papers on ancient Egypt

Depósito Legal: TF-2302-2009

ISSN: $1695-4750$

Imprime: Gráfica Los Majuelos, S.L.L.

imprenta@graficaslosmajuelos.com

Tfno.: 922311455 


\section{Comité Científico \\ III Congreso Ibérico de Egiptología III Congresso Ibérico de Egiptologia}

Miguel Á. Molinero Polo

Universidad de La Laguna

Presidente del Comité Organizador del III Congreso Ibérico de Egiptología

Miembro del Comité Organizador del I Encuentro de Egiptología

Josep Cervelló Autuori

Universitat Autònoma de Barcelona

Presidente del Comité Organizador del II Congreso Ibérico de Egiptologia

José Manuel Galán Allué

Consejo Superior de Investigaciones Cientificas

Director del Proyecto Djehuty, Luxor, Egipto

$\mathrm{M}^{\mathrm{a}}$ Helena Trindade Lopes

Universidad de Lisboa

Directora de la Misión Arqueológica Portuguesa en Menfis

Josep Padró i Parcerisa

Universitat de Barcelona

Director de la Misión Arqueológica de Oxirrinco

Antonio Pérez Largacha

Universidad de Castilla - La Mancha

Miembro del Comité Organizador del I Encuentro de Egiptología

José Ramón Pérez-Accino

Birkbeck College, University of London

Miembro del Comité Organizador del I Encuentro de Egiptología

$\mathrm{M}^{\mathrm{a}}$. Carmen Pérez Díe

Museo Arqueológico Nacional

Directora de la Misión Arqueológica Española en Heracleópolis Magna, Egipto

Covadonga Sevilla Cueva

Universidad Autónoma de Madrid

Miembro del Comité Organizador del I Encuentro de Egiptología 